www.volsu.ru

DOI: https://doi.org/10.15688/jvolsu3.2019.1.7

UDC 338

Submitted: 20.12.2018

LBC 69

Accepted: 11.01.2019

\title{
SOCIAL PARTNERSHIP AS A TOOL TO IMPROVE THE COMPETITIVENESS OF HIGH SCHOOL GRADUATES WITH DISABILITIES IN THE LABOR MARKET
}

\author{
Inna L. Litvinenko \\ Moscow State University of Humanities and Economics, Moscow, Russian Federation \\ Pavel Yu. Tukarev \\ Moscow City University, Moscow, Russian Federation; \\ Russian State Agrarian University named after K.A. Timiryazev, Moscow, Russian Federation
}

\begin{abstract}
Purpose. This article is devoted to the issues of ensuring the competitiveness of persons with disabilities in the modern labor market. The aim is to develop an effective mechanism to promote employment of persons with disabilities on the basis of social partnership. In the course of the research, the authors analyzed the main problems arising in the process of employment of graduates with limited opportunities for health, identified the advantages of an inclusive educational model that allows, unlike the traditional approach, not only to provide comprehensive quality training in various professional fields, but also the accelerated integration of persons with disabilities into the labor sphere and public life, which is one of the most important criteria for the effectiveness of the educational process.

Materials and methods. During the preparation of this article, the authors used scientific works that reveal the issues of employment of persons with disabilities, research experts in the field of inclusive education and improve the competitiveness of graduates with disabilities. The authors used the methods of scientific cognition, comparison, analysis, and system approach as the main research methods.

Results. As the main results of the study, a structural and logical scheme of the Unified Federal Center for the promotion of employment of persons with disabilities in the territory of the Russian Federation was formed, using the advantages of social partnership. The scheme developed by the authors is a universal mechanism that promotes the activation of the process of socialization of this group of citizens and the intensification of the involvement of the human capital of persons with disabilities in the socio-economic processes of our country.

Conclusion. The article outlines the possible ways to improve the effectiveness of social partnership as a system of institutions and mechanisms aimed at harmonizing the interests of the three main parties - the State, the employer and the employee interested in finding effective ways to attract persons with disabilities to the economy.

Key words: social partnership, disabled people, State, labor market, education system, inclusion, resource training center.
\end{abstract}

Citation. Litvinenko I.L., Tukarev P.Yu. Social Partnership as a Tool to Improve the Competitiveness of High School Graduates with Disabilities in the Labor Market. Vestnik Volgogradskogo gosudarstvennogo universiteta. Seriya 3, Ekonomika. Ekologiya [Science Journal of Volgograd State University. Global Economic System], 2019, సi vol. 21, no. 1, pp. 75-82. (in Russian). DOI: https://doi.org/10.15688/jvolsu3.2019.1.7

Дата поступления статьи: 20.12.2018

\section{СОЦИАЛЬНОЕ ПАРТНЕРСТВО НА РЫНКЕ ТРУДА КАК ИНСТРУМЕНТ ПОВЫШЕНИЯ КОНКУРЕНТОСПОСОБНОСТИ ВЫПУСКНИКОВ ВУЗОВ, ИМЕЮЩИХ ИНВАЛИДНОСТЬ}

\section{Инна Леонтьевна Литвиненко}

Московский государственный гуманитарно-экономический университет, г. Москва, Российская Федерация 


\section{УПРАВЛЕНИЕ ЭКОНОМИЧЕСКИМ РАЗВИТИЕМ}

\section{Павел Юрьевич Тукарев}

Московский городской педагогический университет, г. Москва, Российская Федерация; Российский государственный аграрный университет - МСХА им. К.А. Тимирязева,

г. Москва, Российская Федерация

Аннотация. Цель исследования. Настоящая статья посвящена вопросам обеспечения конкурентоспособности лиц с инвалидностью на современном рынке труда. Целью исследования является разработка эффективного механизма содействия трудоустройству лиц с инвалидностью на основе социального партнерства. В ходе исследования авторами проанализированы основные проблемы, возникающие в процессе трудоустройства выпускников, имеющих ограниченные возможности здоровья, выявлены преимущества инклюзивной образовательной модели, позволяющей, в отличие от традиционного подхода, обеспечить не только всесторонне качественную подготовку специалистов в различных профессиональных областях, но и ускоренную интеграцию лиц с инвалидностью в трудовую сферу и общественную жизнь, что является одним из важнейших критериев результативности образовательного процесса.

Материальl и методы. В ходе подготовки данной статьи авторами были использованы научные труды, раскрывающие вопросы трудоустройства лиц с инвалидностью и ограниченными возможностями здоровья, исследования экспертов в области инклюзивного образования и повышения конкурентоспособности выпускников с инвалидностью. В качестве основных методов исследования были применены методы научного познания, сравнение, анализ, системный подход.

Результаты. Основным результатом исследования является сформированная структурно-логическая схема функционирования Единого федерального центра содействия трудоустройству лиц (выпускников) с инвалидностью на территории Российской Федерации с использованием преимущества социального партнерства. Разработанная авторами схема есть универсальный механизм, способствующий активизации процесса социализации данной группы граждан и повышению их конкурентоспособности на рынке труда.

Заключение. Авторами предложены пути повышения эффективности социального партнерства как системы инструментов, направленных на согласование интересов трех ключевых акторов: государства, работодателя и работника, заинтересованных в поиске оптимальных форм привлечения лиц с инвалидностью в экономику России.

Ключевые слова: социальное партнерство, лица с инвалидностью, государство, рынок труда, система образования, инклюзия, ресурсный учебно-методический центр.

Цитирование. Литвиненко И. Л., Тукарев П. Ю. Социальное партнерство на рынке труда как инструмент повышения конкурентоспособности выпускников вузов, имеющих инвалидность // Вестник Волгоградского государственного университета. Серия 3, Экономика. Экология. - 2019. - Т. 21, № 1. - С. 75-82. - DOI: https://doi.org/10.15688/jvolsu3.2019.1.7

\section{Введение}

Интеграция людей с инвалидностью в трудовую деятельность является основным показателем результативности их профессиональной реабилитации и социализации. В настоящий момент ведется постоянный поиск эффективных форм привлечения инвалидов и людей с ограниченными возможностями здоровья (далее OB3) в экономику, так как они могут и изъявляют желание вносить свой посильный вклад в решение стоящих перед государством задач.

Социальное партнерство - система институтов и механизмов, направленных на согласование интересов трех заинтересованных сторон: государства, работодателя и работника (в данном случае инвалида), которая основана на равном сотрудничестве и взаимовыгодных условиях $[6 ; 12 ; 13]$.
О результативности взаимодействия вышеназванных субъектов социального партнерства можно судить по различным показателям. Одним из них является трудоустройство выпускников высших учебных заведений [11].

Процент выпускников, трудоустроившихся по специальности после окончания вуза, является одним из критериев эффективности вуза и важнейшим показателем качества образования. Особенно значим этот показатель для студентов-инвалидов, которым часто приходится прикладывать существенно большие усилия для получения качественного образования, нежели их здоровым сверстникам [10].

Конкурентоспособность выпускника вуза является интегрированным показателем и формируется как результат взаимодействия многих участников, важнейшими из которых выс- 
тупают государство в лице системы образования, высшее учебное заведение и сам студент.

Применительно к здоровым студентам в мире найдены методологические подходы, позволяющие адаптировать студентов к требованиям рынка труда в максимальной степени. В отношении студентов с инвалидностью данная проблема до сих пор не решена, так как образование инвалидов в действительности преследует больше целей, нежели образование здоровых студентов. Кроме необходимых компетенций, предусмотренных образовательной программой, студенты с инвалидностью получают также навыки эффективных коммуникаций в обществе и проходят социализацию [3]. Процесс обучения инвалидов часто сопровождается дополнительными усилиями со стороны преподавателя по обеспечению качества обучения студента, например в форме дополнительных занятий, дублирования каналов передачи информации для студентов с проблемами органов слуха и зрения и иными, в зависимости от нозологии студента [7].

Индивидуальный подход при обучении студента эффективен, однако часто не решает важную задачу обеспечения целостности будущего выпускника как профессионала. Часто при раздельном обучении преподаватель тратит значительные усилия на одни проблемы, прежде всего связанные с формальным освоением материала студентом, и не замечает другие, связанные с использованием этого материала в профессиональной деятельности [15].

Решить указанную проблему позволяет инклюзия. Помещение студента в среду, состоящую как из здоровых лиц, так и из лиц, имеющих инвалидность более тяжелой или более легкой формы, нежели форма инвалидности данного студента, обеспечивает возможность постоянного самоанализа. В частности, студент может:

- выявить свои сильные стороны, позволяющие ему конкурировать на рынке труда наравне со здоровыми выпускниками;

- оценить свои слабости для дальнейшей совместной работы с преподавателями и психологом по их устранению;

- изучить сильные стороны других студентов с аналогичными нозологиями, для того чтобы их перенять и использовать при дальнейшем обучении и в профессиональной деятельности;
- получить опыт общения в смешанных группах, состоящих из здоровых лиц и лиц с инвалидностью, что окажется полезным при дальнейшем трудоустройстве в организацию, в которой работают преимущественно здоровые сотрудники.

Следует отметить, что эффективность инклюзивного образования во многом зависит от сотрудников вуза, реализующих образовательный процесс. Действительно, само по себе пребывание студента с инвалидностью среди здоровых людей не является фактором, однозначно определяющим их дальнейшую конкурентоспособность. Напротив, студенты, особенно обладающие ранимой психикой, могут замкнуться в себе и отказаться от использования тех возможностей, что дает им вуз. Чтобы избежать такого развития событий, следует обеспечить вовлечение студента в жизнь студенческого коллектива с самого начала. При этом следует найти разумный баланс между максимальной загрузкой студента учебой и общественной работой с учетом его нозологии и разумной помощью в целях компенсации тех ограничений здоровья, которые снижают его эффективность при совместной работе смешанного коллектива [2].

\section{Ресурсный учебно-методический центр как инструмент социального партнерства}

Для решения вышеобозначенных проблем существует множество служб содействия трудоустройству и развитию потенциала инвалидов и лиц с ограниченными возможностями здоровья, реализующих принципы социального партнерства. Так, продуктивно развиваются в Москве и субъектах Федерации ресурсные учебно-методические центры (далее - РУМЦ), созданные для помощи вузам и сотрудничающие со структурами, которые занимаются вопросами инклюзивного образования на разных уровнях (см. таблицу).

Важнейшим критерием, определяющим эффективность инклюзивной модели как фактора успешного трудоустройства выпускника, является способность коллектива вуза создавать конкурентную среду. Перед студентом должны изначально ставиться задачи, которые он должен решать на конкурентной осно- 
ве сообразно его возможностям. Успехи и провалы студента должны систематически регистрироваться, после чего с данным студентом должна проводиться работа по анализу ошибок в его поведении и нахождению путей для их устранения в будущем.

Целью такой работы является осознание студентом себя как участника конкурентных отношений, выявление индивидуальных особенностей и в конечном счете формирование наиболее приемлемой модели взаимодействия с внешней средой, являющейся имитацией реального рынка труда [9].

При реализации инклюзивной модели существенная роль должна отводиться общественной работе, так как именно при неформальных контактах между студентами и преподавателями, педагогами, специалистами на различных мероприятиях студенты могут раскрыть свой потенциал с неожиданной стороны. Кроме того, активное участие в общественной жизни вуза позволяет устранить барьеры между здоровыми студентами и студентами с инвалидностью [14].

По окончании вуза, использующего инклюзивную модель образования, студент с инвалидностью имеет конкурентные преимущества перед выпускниками других вузов:
- качественная теоретическая и практическая подготовка;

- благоприятная социальная адаптация;

- способность оптимально применять знания и навыки, полученные по результатам образовательного процесса, с учетом нозологии студента;

- эффективная профессиональная ориентация при возможном наличии первичных контактов с потенциальным работодателем.

На сегодняшний день принять человека с инвалидность готовы 1124 образовательные организации высшего образования в разных регионах Российской Федерации, что является большим прорывом, так как молодые люди с инвалидностью все больше имеют возможность учиться практически по месту жительства, тем самым студенту не придется испытывать трудности адаптации в новом социуме, куда входит не только вуз, но и целый город [8].

\section{Формирование \\ Единого федерального центра содействия трудоустройству лиц (выпускников) с инвалидностью}

По результатам проведенного исследования авторами предлагается создание еди-

Ресурсные учебно-методические центры, действующие на территории Российской Федерации

\begin{tabular}{|c|c|c|}
\hline \multicolumn{3}{|c|}{ Ресурсные учебно-методические центры } \\
\hline $\begin{array}{c}\text { Вятский государственный } \\
\text { университет }\end{array}$ & $\begin{array}{c}\text { Государственный университет } \\
\text { управления }\end{array}$ & $\begin{array}{c}\text { Крымский федеральный } \\
\text { университет им. В.И. Вернадского }\end{array}$ \\
\hline $\begin{array}{c}\text { Московский государственный } \\
\text { гуманитарно-экономический } \\
\text { университет }\end{array}$ & $\begin{array}{c}\text { Московский государственный } \\
\text { психолого-педагогический } \\
\text { университет }\end{array}$ & $\begin{array}{c}\text { Московский государственный } \\
\text { технический университет } \\
\text { им. Н.Э. Баумана } \\
\end{array}$ \\
\hline $\begin{array}{c}\text { Нижегородский государственный } \\
\text { педагогический университет } \\
\text { им. К. Минина } \\
\end{array}$ & $\begin{array}{c}\text { Новосибирский государственный } \\
\text { технический университет }\end{array}$ & $\begin{array}{c}\text { Российская государственная } \\
\text { специализированная академия } \\
\text { искусств (Минкультуры России) }\end{array}$ \\
\hline $\begin{array}{c}\text { Российский государственный } \\
\text { педагогический университет } \\
\text { им. А.И. Герцена }\end{array}$ & $\begin{array}{c}\text { Российский государственный } \\
\text { социальный университет }\end{array}$ & $\begin{array}{c}\text { Российский государственный } \\
\text { университет физической культуры, } \\
\text { спорта, молодежи и туризма } \\
\text { (Минспорт России) }\end{array}$ \\
\hline $\begin{array}{c}\text { Российский университет } \\
\text { транспорта (МИИТ) } \\
\text { (Минтранс России) }\end{array}$ & $\begin{array}{c}\text { Рязанский государственный } \\
\text { медицинский университет } \\
\text { им. академика И.П. Павлова } \\
\text { (Минздрав России) }\end{array}$ & $\begin{array}{c}\text { Северо-Кавказский федеральный } \\
\text { университет }\end{array}$ \\
\hline $\begin{array}{c}\text { Тихоокеанский государственный } \\
\text { университет }\end{array}$ & $\begin{array}{c}\text { Тюменский государственный } \\
\text { университет }\end{array}$ & $\begin{array}{c}\text { Челябинский государственный } \\
\text { университет }\end{array}$ \\
\hline \multicolumn{2}{|c|}{ Череповецкий государственный университет } & деральный университет \\
\hline
\end{tabular}

Примечание. Составлено авторами. 
ной централизованной системы социального партнерства между государством, работодателем и работником (инвалидом или лицом с ограниченными возможностями здоровья), представленной на рисунке $3[1 ; 4 ; 5]$.

Формирование данного механизма предполагает создание при Федеральной службе по труду и занятости (Роструд) Единого федерального центра и региональных подразделений по трудоустройству инвалидов и лиц с ограниченными возможностями здоровья, функционал которых будет направлять и контролировать работу отделов по трудоустройству инвалидов и лиц с ограниченными возможностями здоровья. В свою очередь, отделы по трудоустройству инвалидов и лиц с ограниченными возможностями здоровья представляют собой структурные подразделения при имеющихся центpax занятости населения (см. рисунок).

Работу по содействию трудоустройству инвалидов следует активно и централизованно проводить совместно с некоммерческими организациями (НКО), оказывающими социально ориентированные услуги инвалидам и лицам c OB3, коммерческими рекрутинговыми и кадровыми агентствами, государственными социальными учреждениями и организациями.

Основной задачей Единого федерального центра содействия трудоустройству инвалидов и лиц с ограниченными возможностями здоровья, по мнению авторов, должно быть динамичное повышение количества трудоустроенных лиц с инвалидностью и ОВ3, а также закрепление за ними рабочих мест во избежание формального трудоустройства при формировании отчетности в адрес контролирующих служб.

Для четкой и слаженной работы также предлагается:

- разработка и реализация федеральной целевой программы «Социальное партнерство для содействия трудоустройству инвалидов и

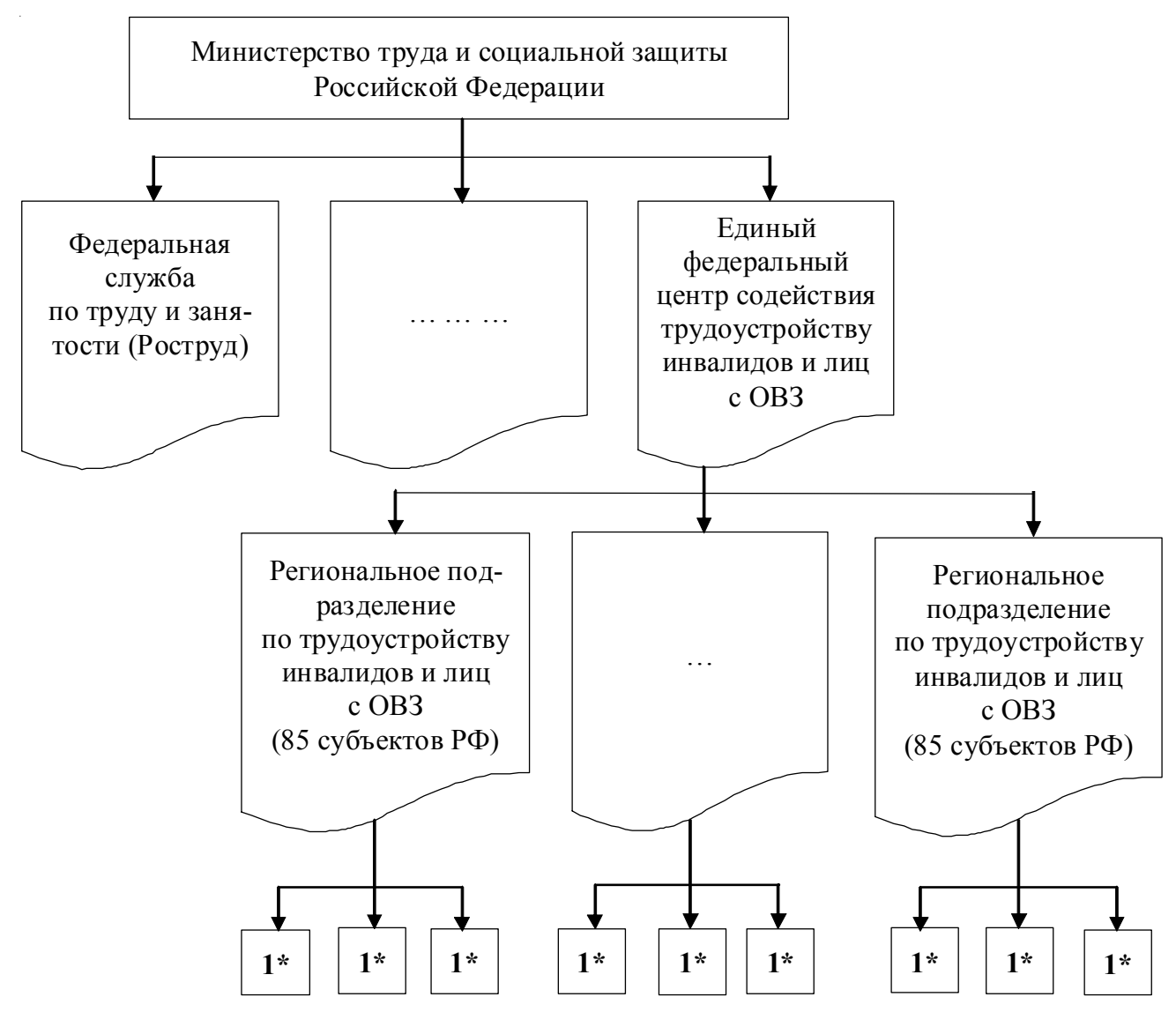

Рисунок. Структурно-логическая схема функционирования Единого федерального центра содействия трудоустройству лиц (выпускников), имеющих инвалидность

Примечание. Составлено авторами. 1 * - отделы по трудоустройству лиц (выпускников) с инвалидностью. 
лиц с ограниченными возможностями здоровья» (далее - Программа);

- формирование и мониторинг Единой федеральной базы обучающихся и выпускников, которые относятся к категории инвалидов и лиц с ОВ3;

- формирование и мониторинг Единой федеральной базы данных коммерческих и некоммерческих организаций, участвующих в Программе;

- создание на базе Министерства труда и социальной защиты Российской Федерации Единой информационной платформы для освещения комплекса мероприятий, направленных на социальную интеграцию и трудоустройство инвалидов и лиц с ОВ3.

\section{Заключение}

Предложенный авторами механизм содействия трудоустройству инвалидов и лиц с ограниченными возможностями здоровья будет способствовать как усилению процесса социализации данной группы граждан, так и интенсификации вовлечения человеческого капитала инвалидов в социально-экономические процессы Российской Федерации.

\section{СПИСОК ЛИТЕРАТУРЫ}

1. Базаева, Т. И. Социальное партнерство как фундаментальная основа развития инновационной экономики / Т. И. Базаева // Управление человеческими ресурсами - основа развития инновационной экономики. -2017 . - № 7. - С. 49-59.

2. Байрамов, В. Д. Профессиональное обучение и карьерное развитие лиц с нарушениями ОДС: сущность и основные детерминанты / В. Д. Байрамов, Д. С. Райдугин // Социально-гуманитарные знания. - 2015. - № 4. - С. 132-140.

3. Давлетшина, Л. Х. Моделирование процесса формирования социально-трудовой компетентности учащихся на основе социального партнерства / Л. Х. Давлетшина // Поволжский педагогический поиск. - 2016. - № 1 (15). - С. 32-34.

4. Данилова, 3. Г. Социальное партнерство как механизм развития качества подготовки кадров / З. Г. Данилова, М. К. Семечева // Профессиональное образование. Столица. - 2017. - № 4. - С. 35-40.

5. Иванова, М. В. Социальное партнерство органов государственной власти Российской Федерации и институтов гражданского общества
/ М. В. Иванова // Академия педагогических идей «Новация». Серия: Студенческий научный вестник. - 2017. - № 9. - С. 70-74.

6. Котикова, О. В. Социальное партнерство в сфере общественный отношений - культурно-исторический аспект / О. В. Котикова // Проблемы современного педагогического образования. 2017. - № 55-9. - С. 80-86.

7. Научно-исследовательская лаборатория по проблемам профессионального образования инвалидов с нарушением опорно-двигательной системы : Фундаментальные научно-исследовательские работы. - М. : Экон-Информ, 2012. - Т. 2. -289 с.

8. Пихтелев, А. М. Социальное партнерство в системе социальных отношений / А. М. Пихтелев // Актуальные проблемы гуманитарных и социально-экономических наук. - 2017. - Т. 11, № 4. C. 59-61.

9. Посохина, С. А. Социальное партнерство как фактор профессионального становления и адаптации студентов вуза / С. А. Посохина // Интерактивная наука. - 2017. - № 6 (16). - С. 32-34.

10. Профессиональная ориентация инвалидов в условиях многоуровневого образования: теория и практика / [А. В. Герасимов и др. ; под общ. ред. В. Д. Байрамова]. - М. : Экон-Информ, 2017. - 451 с.

11. Радостева, М. В. Социальное партнерство в сфере образования на современном этапе / М. В. Радостева // Дискурс. -2017. - № 9 (11). - С. 60-70.

12. Рябова, Т. М. Социальное партнерство в трудовой сфере России / Т. М. Рябова, Ю. В. Кузнецов, О. В. Рогач // Современные научные исследования и инновации. - 2017. - № 4 (72). - С. 821-823.

13. Санжаров, С. Н. Отдельные аспекты социально-трудовых отношений в системе социального партнерства / С. Н. Санжаров // Актуальные проблемы права: теория и практика. - 2016. - № 34. C. $33-42$.

14. Серая, Е. А. Социальное партнерство в сфере труда / Е. А. Серая // Science Time. - 2017. № 5 (41). - C. 111-115.

15. Сергеева, М. Г. Социальное партнерство как фактор инновационного развития профессионального образования / М. Г. Сергеева // В мире научных открытий. -2011. - Т. 15, № 3-1.- С. 609-616.

\section{REFERENCES}

1. Bazaeva T.I. Sotsialnoe partnerstvo kak fundamentalnaya osnova razvitiya innovatsionnoy ekonomiki [Social Partnership as a Fundamental Basis for the Development of an Innovative Economy]. Upravlenie chelovecheskimi resursami - osnova razvitiya innovatsionnoy ekonomiki, 2017, no. 7, pp. 49-59. 
2. Bayramov V.D., Raydugin D.S. Professionalnoe obuchenie i karyernoe razvitie lits $\mathrm{s}$ narusheniyami ODS: sushchnost i osnovnye determinanty [Vocational Training and Career Development of People with Impaired SLM: the Nature and Main Determinants]. Sotsialno-gumanitarnye znaniya, 2015, no. 4, pp. 132-140.

3. Davletshina L.Kh. Modelirovanie protsessa formirovaniya sotsialno-trudovoy kompetentnosti uchashchikhsya na osnove sotsialnogo partnerstva [Modeling the Process of Formation of Social and Labor Competence of Students on the Basis of Social Partnership]. Povolzhskiy pedagogicheskiy poisk, 2016, no. 1 (15), pp. 32-34.

4. Danilova Z.G., Semecheva M.K. Sotsialnoe partnerstvo kak mekhanizm razvitiya kachestva podgotovki kadrov [Social Partnership as a Mechanism for the Development of Quality Training]. Professionalnoe obrazovanie. Stolitsa, 2017, no. 4, pp. 35-40.

5. Ivanova M.V. Sotsialnoe partnerstvo organov gosudarstvennoy vlasti Rossiyskoy Federatsii i institutov grazhdanskogo obshchestva [Social Partnership of State Authorities of the Russian Federation and Civil Society Institutions]. Akademiya pedagogicheskikh idey "Novatsiya». Seriya: Studencheskiy nauchnyy vestnik, 2017, no. 9, pp. 70-74.

6. Kotikova O.V. Sotsialnoe partnerstvo v sfere obshchestvennyy otnosheniy - kulturno-istoricheskiy aspekt [Social Partnership in the Sphere of Social Relations - Cultural and Historical Aspect]. Problemy sovremennogo pedagogicheskogo obrazovaniya, 2017, no. 55-9, pp. 80-86.

7. Nauchno-issledovatelskaya laboratoriya po problemam professionalnogo obrazovaniya invalidov $s$ narusheniem oporno-dvigatelnoy sistemy: Fundamentalnye nauchno-issledovatelskie raboty [Research Laboratory on Vocational Education Problems of Persons with Disabilities of the Musculoskeletal System: Fundamental Research Works]. Moscow, Ekon-Inform Publ., 2012. vol. 2. 289 p.
8. Pikhtelev A.M. Sotsialnoe partnerstvo v sisteme sotsialnykh otnosheniy [Social Partnership in the System of Social Relations]. Aktualnye problemy gumanitarnykh i sotsialno-ekonomicheskikh nauk, 2017, vol. 4, no. 11, pp. 59-61.

9. Posokhina S.A. Sotsialnoe partnerstvo kak faktor professionalnogo stanovleniya i adaptatsii studentov vuza [Social Partnership as a Factor of Professional Formation and Adaptation of University Students]. Interaktivnaya nauka, 2017, no. 6 (16), pp. 32-34.

10. Gerasimov A.V., et al. Professionalnaya orientatsiya invalidov v usloviyakh mnogourovnevogo obrazovaniya: teoriya i praktika [Professional orientation of persons with disabilities in a multi-level education: theory and practice]. Moscow, Ekon-Inform Publ., 2017.451 p.

11. Radosteva M.V. Sotsialnoe partnerstvo v sfere obrazovaniya na sovremennom etape [Social Partnership in the Field of Education at the Present Stage]. Diskurs, 2017, no. 9 (11), pp. 60-70.

12. Ryabova T.M., Kuznetsov Yu.V., Rogach O.V. Sotsialnoe partnerstvo v trudovoy sfere Rossii [Social Partnership in the Labor Sphere of Russia]. Sovremennye nauchnye issledovaniya i innovatsii, 2017, no. 4 (72), pp. 821-823.

13. Sanzharov S.N. Otdelnye aspekty sotsialnotrudovykh otnosheniy $\mathrm{v}$ sisteme sotsialnogo partnerstva [Some Aspects of Social and Labor Relations in the System of Social Partnership]. Aktualnye problemy prava: teoriya i praktika, 2016, no. 34, pp. 33-42.

14. Seraya E.A. Sotsialnoe partnerstvo v sfere truda [Social Partnership in the World of Labour]. Science Time, 2017, no. 5 (41), pp. 111-115.

15. Sergeeva M.G. Sotsialnoe partnerstvo kak faktor innovatsionnogo razvitiya professionalnogo obrazovaniya [Social Partnership as a Factor of Innovative Development of Vocational Education]. V mire nauchnykh otkrytiy, 2011, vol. 15, no. 3.1, pp. 609-616.

\section{Information about the Authors}

Inna L. Litvinenko, Candidate of Sciences (Economics), Associate Professor of Department of Management and Entrepreneurship, Moscow State University of Humanities and Economics, Losinoostrovskaya St., 49, 107150 Moscow, Russian Federation, innalitvinenko@yandex.ru, https:// orcid.org/0000-0002-6102-5012

Pavel Yu. Tukarev, Master Student, Moscow City University, Deputy Head of the Contracts Department, $2^{\text {nd }}$ Selskokhozyaystvennyy proezd, 4, 129226 Moscow, Russian Federation; Russian State Agrarian University named after K.A. Timiryazev, Timiryazevskaya St., 49, 127550 Moscow, Russian Federation, tukarevpavel@mail.ru, https://orcid.org/0000-0003-3278-8181 


\section{УПРАВЛЕНИЕ ЭКОНОМИЧЕСКИМ РАЗВИТИЕМ}

\section{Информация об авторах}

Инна Леонтьевна Литвиненко, кандидат экономический наук, доцент кафедры управления и предпринимательства, Московский государственный гуманитарно-экономический университет, ул. Лосиноостровская, 49, 107150 г. Москва, Российская Федерация, innalitvinenko@yandex.ru, https://orcid.org/0000-0002-6102-5012

Павел Юрьевич Тукарев, магистрант, Московский городской педагогический университет, 2-й Сельскохозяйственный проезд, 4, 129226 г. Москва, Российская Федерация; заместитель руководителя Управления контрактной службы и договорной работы, Российский государственный аграрный университет - МСXА им. К.А.Тимирязева, ул. Тимирязевская, 49, 127550 г. Москва, Российская Федерация, tukarevpavel@mail.ru, https://orcid.org/0000-0003-3278-8181 